\title{
Predicting Ultimate Loads for Wind Turbine Design
}

Peter Hauge Madsen

Risø National Laboratory

Kirk Pierce, Marshall Buhl

National Wind Technology Center

National Renewable Energy Laboratory

Presented at

AIAA/ASME Wind Energy Symposium

Reno, Nevada

January 11-14, 1999

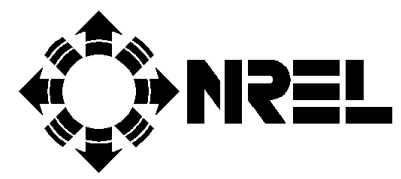

National Renewable Energy Laboratory 1617 Cole Boulevard

Golden, Colorado 80401-3393

A national laboratory of the U.S. Department of Energy Managed by Midwest Research Institute for the U.S. Department of Energy under contract No. DE-AC36-83CH10093

Work performed under task number WE903330

November 1998 


\section{NOTICE}

This report was prepared as an account of work sponsored by an agency of the United States government. Neither the United States government nor any agency thereof, nor any of their employees, makes any warranty, express or implied, or assumes any legal liability or responsibility for the accuracy, completeness, or usefulness of any information, apparatus, product, or process disclosed, or represents that its use would not infringe privately owned rights. Reference herein to any specific commercial product, process, or service by trade name, trademark, manufacturer, or otherwise does not necessarily constitute or imply its endorsement, recommendation, or favoring by the United States government or any agency thereof. The views and opinions of authors expressed herein do not necessarily state or reflect those of the United States government or any agency thereof.

Available to DOE and DOE contractors from:

Office of Scientific and Technical Information (OSTI)

P.O. Box 62

Oak Ridge, TN 37831

Prices available by calling (423) $576-8401$

Available to the public from:

National Technical Information Service (NTIS)

U.S. Department of Commerce

5285 Port Royal Road

Springfield, VA 22161

(703) 487-4650 


\title{
PREDICTING ULTIMATE LOADS FOR WIND TURBINE DESIGN
}

\author{
Peter Hauge Madsen ${ }^{*}$, Kirk Pierce ${ }^{\dagger}$ and Marshall Buhl ${ }^{\dagger}$ \\ * Dept. of Wind Energy and Atmospheric Physics, Risø National Laboratory, Denmark \\ $\uparrow$ National Renewable Energy Laboratory, Golden CO, USA
}

\begin{abstract}
This paper addresses the statistical uncertainty of loads prediction using structural dynamics simulation codes and the requirements for the number and duration of simulations for obtaining robust load estimates. Substantial statistical variation is observed in loads data and a statistical model that enables extrapolation and determination of quantiles is presented. Further reduction in the numerical work necessary to determine extreme loads with an acceptable uncertainty is possible using a stochastic process model for the dynamic responses. A procedure allowing for a slightly nonGaussian response is proposed and satisfactory accuracy is found. Finally, the extreme loads from the revised IEC 61400-1 wind turbine standard on safety requirements are calculated for the turbine, and loads from the gust models and the properly extrapolated simulation extremes are compared.
\end{abstract}

\section{INTRODUCTION}

In general the verification of a wind turbine design comprises investigation of the strength with regard to both fatigue loads and ultimate loads. For several components the design is limited by ultimate loading. Ultimate loading may arise from extreme situations such as extreme wind speeds with a parked rotor, at lower wind speeds during operation where the effect of gusty wind is combined with a significant periodic response, or special events such as start-up, shutdown, or during yawing.

The concept of ultimate loads from extreme wind is very similar to the traditional approach to wind loading adopted in codes for wind action on structures, e.g., ISO 4354. ${ }^{1}$ This approach was established by Davenport $^{2}$ and was applied to wind turbines in Madsen. ${ }^{3}$ This statistical approach forms the basis for the Danish wind turbine design standard. ${ }^{4}$ However, in recent years aero-elastic time-domain load prediction codes have been developed and verified, and are now widely used by the industry. These codes are used not only for calculation of operational loads but also for extreme wind loads.

Present design practices and recognized standards for wind turbine loads and safety, e.g., IEC $61400-1,{ }^{5}$ require ultimate loads from the fluctuating wind to be predicted using both discrete gust models and advanced simulations of the 3-D stochastic turbulent wind field as input to comprehensive aero-elastic models. Whereas the gust models give reproducible results, they are a coarse representation of the wind, and are furthermore difficult to adjust to the actual site and wind turbine. On the other hand, simulations using accurate and validated comprehensive turbulence and structural dynamics codes give realistic results but share the difficulties in defining the ultimate load for design with actual fullscale load measurements. The stochastic nature of the turbulent wind input causes the calculated extreme loads to be random quantities with significant variation. Thus, one response simulation will give one realization of the stochastic load extreme, a value furthermore associated with the duration of the simulation rather than of the wind turbine design situation.

Using codes for the aero-elastic response and turbulence developed at Risø, Thomsen et al. ${ }^{6}$ investigated the estimation of extreme loads with reference to two load cases from the Danish wind turbine design standard. While the analysis was limited to the flap-wise blade bending moment, a considerable variation in the largest load value was observed, and predicting the mean extreme using the extreme value distribution from a Gaussian process derived by Davenport ${ }^{7}$ had some success in terms of less variation.

The present work continues this effort using different models to calculate the primary loads for a different wind turbine. The load cases are chosen with reference to the IEC 61400-1 load cases and focuses on the loads on the parked wind turbine at the extreme wind speed and on the running wind turbine at rated and cut-out wind speed. Additional details can be found in Madsen et al. ${ }^{8}$

\section{THE WIND TURBINE MODEL}

For this study a model of the NREL/NWTC Unsteady Aerodynamics Experiment Phase III turbine was used, see Figure 1. The turbine has a rotor diameter of $10 \mathrm{~m}$ and nominal rotor speed of $72 \mathrm{rpm}$. It is a three bladed turbine with a hub height of $17 \mathrm{~m}$ and operates in free yaw downwind of the tower. The dimensions, frequencies, and other properties of the turbine are described in detail in Schepers et al. ${ }^{9}$ The commercially 


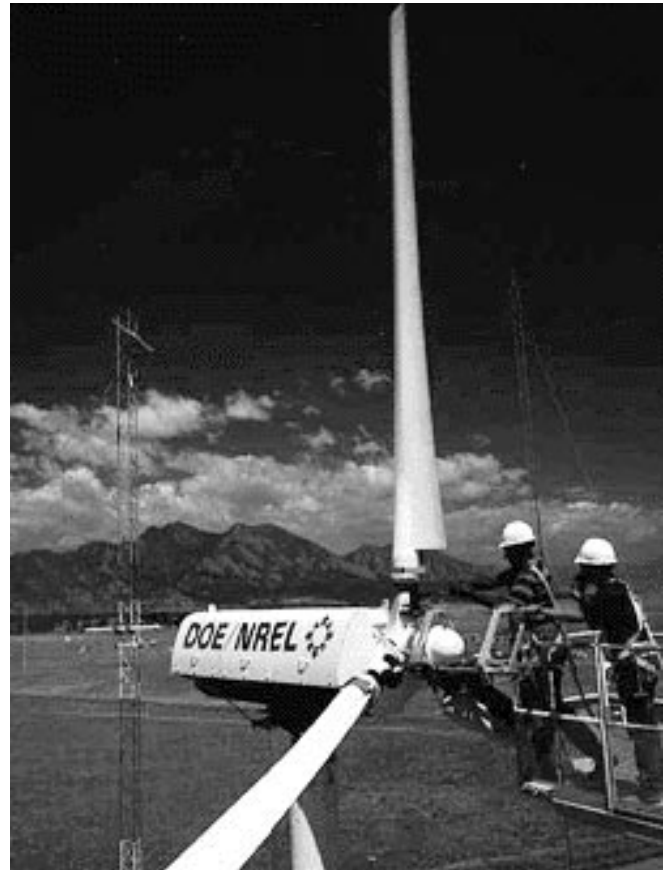

Figure 1. National Renewable Energy Laboratory/National Wind Technology Center Unsteady Aerodynamics Experiment Phase III wind turbine

available ADAMS ${ }^{\circledR}$ code linked with the AeroDyn aerodynamic subroutines ${ }^{10}$ was used for all simulations.

The ADAMS model was developed from extensive modal tests and system component weights. Modal tests and component weighing were performed for individual components and assemblies. Modal tests were performed on the instrumented blade, one uninstrumented blade, the tower alone, and the nacelletower assembly. The nacelle was weighed and the inertia properties were determined from a bi-filar pendulum test. The blades were weighed to determine mass and center of gravity location. The ADAMS model was tuned to match the measured masses, center of masses, and frequencies in the same configurations used in modal tests. The model has 177 degrees of freedom. Six twisted tapered beam elements and one standard beam element model each blade. The tower is modeled with eight beam elements. Other degrees of freedom include the rotor rotational degree of freedom, low speed shaft torsion, and yaw. Nonlinear forces model the tower guy wires. The torque speed relation of the generator was determined from measured data.

The model used in this study is thus considered well validated and is expected to give realistic load predictions.

\section{LOAD CALCULATIONS}

In this study two design conditions of the IEC 61400-1 have been considered:
Table 1. Load Cases

\begin{tabular}{|l|l|l|l|l|}
\hline $\begin{array}{l}\text { Design situa- } \\
\text { tion - Load } \\
\text { case }\end{array}$ & $\begin{array}{l}\text { Wind } \\
\text { speed } \\
(10 \mathrm{~min} \\
\text { aver. })\end{array}$ & $\begin{array}{l}\text { Power } \\
\text { law } \\
\text { exponent } \\
\alpha\end{array}$ & $\begin{array}{l}\text { Target } \\
\text { turb. } \\
\text { intensity } \\
\mathrm{I}_{\mathrm{u}}{ }^{*}\end{array}$ & $\begin{array}{l}\text { Refer- } \\
\text { ence } \\
\text { height }\end{array}$ \\
\hline $\begin{array}{l}\text { Operation at } \\
\text { rated wind } \\
\text { speed }\end{array}$ & $14 \mathrm{~m} / \mathrm{s}$ & 0.2 & $17 \%$ & $16.8 \mathrm{~m}$ \\
\hline $\begin{array}{l}\text { Operation at } \\
\text { cut-out wind } \\
\text { speed }\end{array}$ & $20 \mathrm{~m} / \mathrm{s}$ & 0.2 & $17 \%$ & $16.8 \mathrm{~m}$ \\
\hline $\begin{array}{l}\text { Parked at } \\
\text { extreme wind } \\
\text { speed }\end{array}$ & $45 \mathrm{~m} / \mathrm{s}$ & 0.2 & $17 \%$ & $16.8 \mathrm{~m}$ \\
\hline
\end{tabular}

- Power Production

- Parked (standing still or idling).

During the Power Production design condition the wind turbine was modeled as operating in its natural mode, i.e., free yaw and a nearly constant rotation speed of $72 \mathrm{rpm}$ (with small variations due to the generator slip).

Similarly for the Parked design situation the wind turbine was modeled realistically with free yaw and a fixed rotor with blade \#1 pointing vertically upwards.

The wind input for the design situations is summarized in Table 1. While the load cases correspond to Design Load Case 1.1 and 6.1 in IEC 61400-1, the wind input is not related to a specific wind turbine class. The wind during the parked situation is modeled as being turbulent at a given mean wind speed rather than by a constant extreme wind.

In all load cases the Kaimal spectral model for the three-dimensional wind turbulence given in IEC 614001 annex B has been used. This includes the value for coherence decrements, ratio between velocity component standard deviations, and integral length scales.

Other parameters such as the power law exponent during the parked situation and the turbulence level were given by the turbulence simulation tool and could not be changed without rewriting the code.

For each of the load cases 100 simulation runs were performed. Each simulation had a duration of $610 \mathrm{sec}-$ onds, of which the first 10 seconds were excluded to eliminate start-up transients.

The following primary signals and loads were retained for further analysis (the wind speed was kept only as a reference):

- Wind speed in $\mathrm{m} / \mathrm{s}$

WindSpd

- Blade root out-of-plane bending moment

- Blade root in-plane bending moment B1_Moop

B1_Mip

- Yaw bearing force in longitudinal direc- YB_Fdw tion (thrust)

- Yaw bearing force in lateral direction

- Yaw bearing pitching moment

- Yaw bearing rolling moment YB_Mpitch YB_Mroll 
The main statistics of the load calculations are summarized in Tables 2, 3, and 4. The mean, standard deviation, and coefficient of variation (COV) are listed for these main statistical parameters.

Table 2. Statistics - Power Production at $14 \mathrm{~m} / \mathrm{s}$

\begin{tabular}{|c|c|c|c|c|c|c|c|c|}
\hline \multicolumn{2}{|c|}{ Run statistics } & $\begin{array}{c}\text { WindSpd } \\
\mathrm{m} / \mathrm{s}\end{array}$ & $\begin{array}{c}\text { B1_Moop } \\
\overline{\mathrm{kNNm}}\end{array}$ & $\begin{array}{c}\text { B1_Mip } \\
\mathrm{KN}\end{array}$ & $\begin{array}{c}\text { YB_Fdw } \\
\overline{\mathrm{kN}}\end{array}$ & $\begin{array}{c}\text { YB_Fcw } \\
\overline{\mathrm{kN}}\end{array}$ & $\begin{array}{c}\text { YB_Mpitch } \\
\overline{\mathrm{k} N m}\end{array}$ & $\begin{array}{c}\text { YB_Mroll } \\
\mathrm{kNm}\end{array}$ \\
\hline \multirow{3}{*}{ Mean } & Mean & 14.10 & 0.86 & 0.74 & 2.35 & -0.04 & -3.09 & -2.89 \\
& St.dev & 0.027 & 0.004 & 0.004 & 0.004 & 0.002 & 0.017 & 0.012 \\
& COV & $0.2 \%$ & $0.5 \%$ & $0.5 \%$ & $0.2 \%$ & $-6.2 \%$ & $-0.6 \%$ & $-0.4 \%$ \\
\hline \multirow{2}{*}{ Stand } & Mean & 2.18 & 0.65 & 0.92 & 0.50 & 0.16 & 1.27 & 0.32 \\
Deviat. & St.dev & 0.052 & 0.016 & 0.002 & 0.019 & 0.006 & 0.046 & 0.016 \\
& COV & $2.4 \%$ & $2.4 \%$ & $0.2 \%$ & $3.8 \%$ & $3.7 \%$ & $3.6 \%$ & $5.2 \%$ \\
\hline \multirow{2}{*}{ Mean } & Mean & 0.43 & 3.20 & 1.28 & 2.43 & 2.13 & 2.37 & 1.12 \\
cross. freq. & St.dev & 0.031 & 0.053 & 0.012 & 0.039 & 0.022 & 0.086 & 0.050 \\
& COV & $7.3 \%$ & $1.6 \%$ & $0.9 \%$ & $1.6 \%$ & $1.0 \%$ & $3.6 \%$ & $4.4 \%$ \\
\hline \multirow{3}{*}{ Skewness } & Mean & 0.14 & 0.05 & 0.03 & -0.02 & 0.10 & -0.04 & 0.65 \\
& St.dev & 0.159 & 0.032 & 0.003 & 0.069 & 0.055 & 0.091 & 0.320 \\
& COV & $114.2 \%$ & $62.1 \%$ & $13.1 \%$ & $-301.7 \%$ & $56.4 \%$ & $-237.8 \%$ & $49.1 \%$ \\
\hline Abs. & Mean & 21.79 & 4.02 & 2.91 & 4.43 & 0.74 & 8.48 & 3.90 \\
Maxi- & St.dev & 0.873 & 0.330 & 0.109 & 0.202 & 0.105 & 0.576 & 0.094 \\
mum & COV & $4.0 \%$ & $8.2 \%$ & $3.8 \%$ & $4.6 \%$ & $14.1 \%$ & $6.8 \%$ & $2.4 \%$ \\
\hline
\end{tabular}

Table 3. Statistics - Power Production at $20 \mathrm{~m} / \mathrm{s}$

\begin{tabular}{|c|c|c|c|c|c|c|c|c|}
\hline \multicolumn{2}{|c|}{ Run statisticss } & $\begin{array}{c}\text { WindSpd } \\
\mathrm{m} / \mathrm{s}\end{array}$ & $\begin{array}{c}\text { B1_Moop } \\
\text { kNm }\end{array}$ & $\begin{array}{c}\text { B1_Mip } \\
\text { KNm }\end{array}$ & $\begin{array}{c}\text { YB_Fdw } \\
\overline{\mathrm{kN}}\end{array}$ & $\begin{array}{c}\text { YB_Fcw } \\
\mathrm{kN}\end{array}$ & $\begin{array}{c}\text { YB_Mpitch } \\
\text { kNm }\end{array}$ & $\begin{array}{c}\text { YB_Mroll } \\
\mathrm{kNm}\end{array}$ \\
\hline \multirow{3}{*}{ Mean } & Mean & 20.14 & 1.25 & 0.81 & 2.88 & -0.04 & -3.50 & -3.20 \\
\hline & St.dev & 0.035 & 0.005 & 0.003 & 0.006 & 0.002 & 0.013 & 0.012 \\
\hline & $\mathrm{COV}$ & $0.2 \%$ & $0.4 \%$ & $0.4 \%$ & $0.2 \%$ & $-4.4 \%$ & $-0.4 \%$ & $-0.4 \%$ \\
\hline \multirow{3}{*}{$\begin{array}{l}\text { Stand. } \\
\text { Deviat. }\end{array}$} & Mean & 3.11 & 0.82 & 0.94 & 0.79 & 0.22 & 1.571 & 0.53 \\
\hline & St.dev & 0.062 & 0.020 & 0.002 & 0.030 & 0.011 & 0.057 & 0.011 \\
\hline & $\mathrm{COV}$ & $2.0 \%$ & $2.4 \%$ & $0.2 \%$ & $3.8 \%$ & $4.9 \%$ & $3.6 \%$ & $2.0 \%$ \\
\hline \multirow{3}{*}{$\begin{array}{c}\text { Mean } \\
\text { cross. freq. }\end{array}$} & Mean & 0.51 & 3.20 & 1.40 & 2.15 & 2.18 & 2.53 & 0.79 \\
\hline & St.dev & 0.035 & 0.053 & 0.020 & 0.031 & 0.018 & 0.071 & 0.037 \\
\hline & $\mathrm{COV}$ & $6.9 \%$ & $1.6 \%$ & $1.4 \%$ & $1.4 \%$ & $0.8 \%$ & $2.8 \%$ & $4.7 \%$ \\
\hline \multirow{3}{*}{ Skewness } & Mean & 0.137 & 0.01 & 0.01 & 0.79 & 0.22 & 0.05 & -0.53 \\
\hline & St.dev & 0.131 & 0.046 & 0.005 & 0.030 & 0.011 & 0.084 & 0.088 \\
\hline & $\mathrm{COV}$ & 0.960 & $466.8 \%$ & $35.6 \%$ & $3.8 \%$ & $4.9 \%$ & $158.0 \%$ & $-16.8 \%$ \\
\hline \multirow{3}{*}{$\begin{array}{l}\text { Abs. } \\
\text { Maxi- } \\
\text { mum }\end{array}$} & Mean & 31.43 & 5.14 & 3.35 & 6.21 & 1.10 & 10.23 & 5.24 \\
\hline & St.dev & 1.259 & 0.498 & 0.160 & 0.379 & 0.161 & 0.821 & 0.223 \\
\hline & $\mathrm{COV}$ & $4.0 \%$ & $9.7 \%$ & $4.8 \%$ & $6.1 \%$ & $14.7 \%$ & $8.0 \%$ & $4.2 \%$ \\
\hline
\end{tabular}

Table 4. Statistics - Parked at $45 \mathrm{~m} / \mathrm{s}$

\begin{tabular}{|c|c|c|c|c|c|c|c|c|}
\hline \multicolumn{2}{|c|}{ Run statistics } & $\begin{array}{l}\text { WindSpd } \\
\mathrm{m} / \mathrm{s}\end{array}$ & $\begin{array}{c}\text { B1_Moop } \\
\text { KNm }\end{array}$ & $\begin{array}{c}\text { B1_Mip } \\
\text { kNm }\end{array}$ & $\underset{\overline{\mathrm{kN}}}{\mathrm{YB} F d w}$ & $\underset{\mathrm{kN}}{\mathrm{YB} F \mathrm{Fcw}}$ & YB_Mpitch & $\begin{array}{c}\text { YB_Mroll } \\
\mathrm{kNm}\end{array}$ \\
\hline \multirow{3}{*}{ Mean } & Mean & 45.31 & 7.90 & 1.40 & 8.36 & -0.07 & -7.86 & -5.39 \\
\hline & St.dev & 0.061 & 0.020 & 0.003 & 0.022 & 0.001 & 0.017 & 0.012 \\
\hline & $\mathrm{COV}$ & $0.1 \%$ & $0.2 \%$ & $0.2 \%$ & $0.3 \%$ & $-1.1 \%$ & $-0.2 \%$ & $-0.2 \%$ \\
\hline \multirow{3}{*}{$\begin{array}{l}\text { Stand. } \\
\text { Deviat. }\end{array}$} & Mean & 6.99 & 2.61 & 0.65 & 3.89 & 0.69 & 3.82 & 1.59 \\
\hline & St.dev & 0.088 & 0.031 & 0.005 & 0.084 & 0.021 & 0.073 & 0.019 \\
\hline & $\mathrm{COV}$ & $1.3 \%$ & $1.2 \%$ & $0.7 \%$ & $2.2 \%$ & $3.1 \%$ & $1.9 \%$ & $1.2 \%$ \\
\hline \multirow{3}{*}{$\begin{array}{c}\text { Mean } \\
\text { cross. freq. }\end{array}$} & Mean & 0.77 & 1.78 & 4.48 & 1.67 & 2.24 & 2.21 & 1.18 \\
\hline & St.dev & 0.035 & 0.053 & 0.058 & 0.033 & 0.017 & 0.037 & 0.032 \\
\hline & $\mathrm{COV}$ & $4.6 \%$ & $3.0 \%$ & $1.3 \%$ & $2.0 \%$ & $0.8 \%$ & $1.7 \%$ & $2.7 \%$ \\
\hline \multirow{3}{*}{ Skewness } & Mean & 0.13 & 0.32 & 0.17 & 0.22 & -0.02 & -0.20 & -0.40 \\
\hline & St.dev & 0.088 & 0.089 & 0.037 & 0.074 & 0.013 & 0.063 & 0.082 \\
\hline & $\mathrm{COV}$ & $66.5 \%$ & $27.8 \%$ & $21.4 \%$ & $33.7 \%$ & $-67.0 \%$ & $-32.0 \%$ & $-20.5 \%$ \\
\hline \multirow{3}{*}{$\begin{array}{l}\text { Abs. } \\
\text { Maxi- } \\
\text { mum }\end{array}$} & Mean & 71.81 & 20.10 & 4.30 & 25.38 & 3.08 & 25.24 & 12.61 \\
\hline & St.dev & 2.909 & 1.594 & 0.302 & 2.013 & 0.294 & 2.014 & 0.839 \\
\hline & $\mathrm{COV}$ & $4.1 \%$ & $7.9 \%$ & $7.0 \%$ & $7.9 \%$ & $9.5 \%$ & $8.0 \%$ & $6.7 \%$ \\
\hline
\end{tabular}


The mean crossing frequency is a characteristic frequency for the signal, and is defined as the average frequency with which the signal crosses its mean value from below. In the tables the mean crossing frequency is determined directly from the time series by counting the number of up mean-crossings.

Since the time series represents the load signals sampled at $25 \mathrm{~Hz}$ the extremes of the time series may underpredict the extremes of the signal. Therefore, after a local extreme has been identified from three consecutive points in the time series, a $2^{\text {nd }}$ order polynomial is fit to the three points. The data extreme is then replaced by the extreme of the polynomial. The effect is not large, but is believed to give a more accurate estimate of the extremes.

If we assume that the load case under consideration properly reflects a design driving condition two questions immediately come to mind:

- How to determine the characteristic/representative ultimate load for design verification, and

- How many simulations are required for a sufficiently accurate estimate of the ultimate load?

From the summary statistics in Tables 2, 3, and 4, it is seen that although only the seed parameter for the simulation has been changed from run to run, and variability of the wind parameters has not been accounted for, the extremes show a considerable variation.

The variation in calculated extremes is shown in Figure 2 for three of the loads during the parked rotor load case at $45 \mathrm{~m} / \mathrm{s}$ wind speed. The horizontal axis is simply the simulation run number while the vertical axis is the largest absolute value observed during that run for the load in question.

It is clear from the figures that two arbitrarily selected simulations may give considerably different extreme values and ultimate loads. This means performing a few simulations and selecting the average or the largest extreme load as the ultimate load will neither give reproducible results, nor can the results be extrapolated to a characteristic value defined by a quantile or a different duration of the load case. In general it is doubtful that the uncertainty in extreme value from a few simulations can be properly accounted for with total load safety factors of the order of 1.3.

It is therefore necessary to develop a procedure and rationale for the analysis of the extreme loads from such simulations. With the statistical variation from one time series to the next, a statistical analysis must therefore be performed of the observed extreme or peak loads in order to determine a representative design load.

\section{EXTREME STATISTICS}

Under rather weak assumptions (the distribution of the signal is unbounded and approaches zero exponentially for large values, Gumbel ${ }^{11}$ ) the asymptotic distribution of extremes is the Extreme Value Type 1 (EV1) distribution.

The EV1 distribution function is given by the expression

$$
F(x ; \alpha, \beta)=\exp (-\exp (-\alpha(x-\beta)))
$$

Where $\alpha$ and $\beta$ are the scale and location parameters respectively.
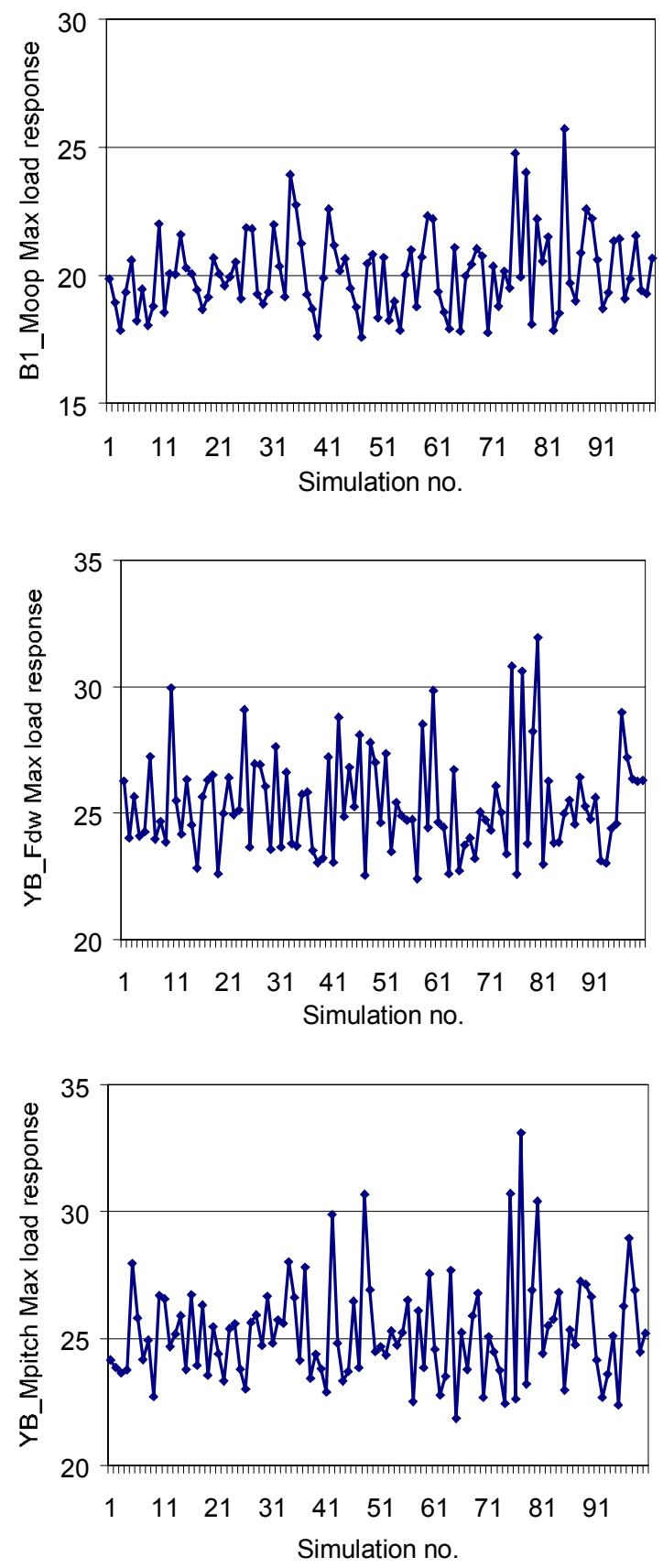

Figure 2. Load extremes during 10-minute simulations, parked at $45 \mathrm{~m} / \mathrm{s}$ 
Table 5. Parameters in Fitted Extreme Value Type 1 Distribution for the Load Extremes

\begin{tabular}{|c|c|c|c|c|c|c|c|c|}
\hline \multicolumn{2}{|c|}{$\begin{array}{c}\text { EV1-dist. From } 100 \text { time } \\
\text { series }\end{array}$} & $\begin{array}{c}\text { WindSpd } \\
\mathrm{m} / \mathrm{s}\end{array}$ & $\begin{array}{c}\text { B1_Moop } \\
\text { kNm }\end{array}$ & $\begin{array}{c}\text { B1_Mip } \\
\text { kNm }\end{array}$ & $\underset{\mathrm{kN}}{\mathrm{YB} F \mathrm{Fdw}}$ & $\begin{array}{c}\text { YB_Fcw } \\
\mathrm{kN}\end{array}$ & $\begin{array}{c}\text { YB_Mpitch } \\
\text { kNm }\end{array}$ & $\begin{array}{c}\text { YB_Mroll } \\
\text { kNm }\end{array}$ \\
\hline \multirow{4}{*}{$\begin{array}{l}\text { Power } \\
\text { production - } \\
14 \mathrm{~m} / \mathrm{s}\end{array}$} & alfa & 1.44 & 3.69 & 11.83 & 6.08 & 11.99 & 2.14 & 14.09 \\
\hline & beta & 21.39 & 3.87 & 2.86 & 4.33 & 0.69 & 8.21 & 3.86 \\
\hline & mean & 21.79 & 4.02 & 2.91 & 4.43 & 0.74 & 8.48 & 3.90 \\
\hline & st.dev. & 0.89 & 0.35 & 0.11 & 0.21 & 0.11 & 0.60 & 0.09 \\
\hline \multirow{4}{*}{$\begin{array}{l}\text { Power } \\
\text { production - } \\
20 \mathrm{~m} / \mathrm{s}\end{array}$} & alfa & 1.01 & 2.70 & 8.27 & 3.40 & 7.81 & 1.52 & 5.72 \\
\hline & beta & 30.86 & 4.93 & 3.28 & 6.04 & 1.02 & 9.85 & 5.14 \\
\hline & mean & 31.43 & 5.14 & 3.35 & 6.21 & 1.10 & 10.23 & 5.24 \\
\hline & st.dev. & 1.27 & 0.47 & 0.16 & 0.38 & 0.16 & 0.84 & 0.22 \\
\hline \multirow{4}{*}{$\begin{array}{l}\text { Parked - } \\
45 \mathrm{~m} / \mathrm{s}\end{array}$} & alfa & 0.44 & 0.79 & 4.10 & 0.62 & 4.26 & 0.64 & 1.50 \\
\hline & beta & 70.50 & 19.37 & 4.16 & 24.46 & 2.95 & 24.34 & 12.22 \\
\hline & mean & 71.81 & 20.10 & 4.30 & 25.38 & 3.08 & 25.24 & 12.61 \\
\hline & st.dev. & 2.91 & 1.63 & 0.31 & 2.05 & 0.30 & 2.01 & 0.86 \\
\hline
\end{tabular}
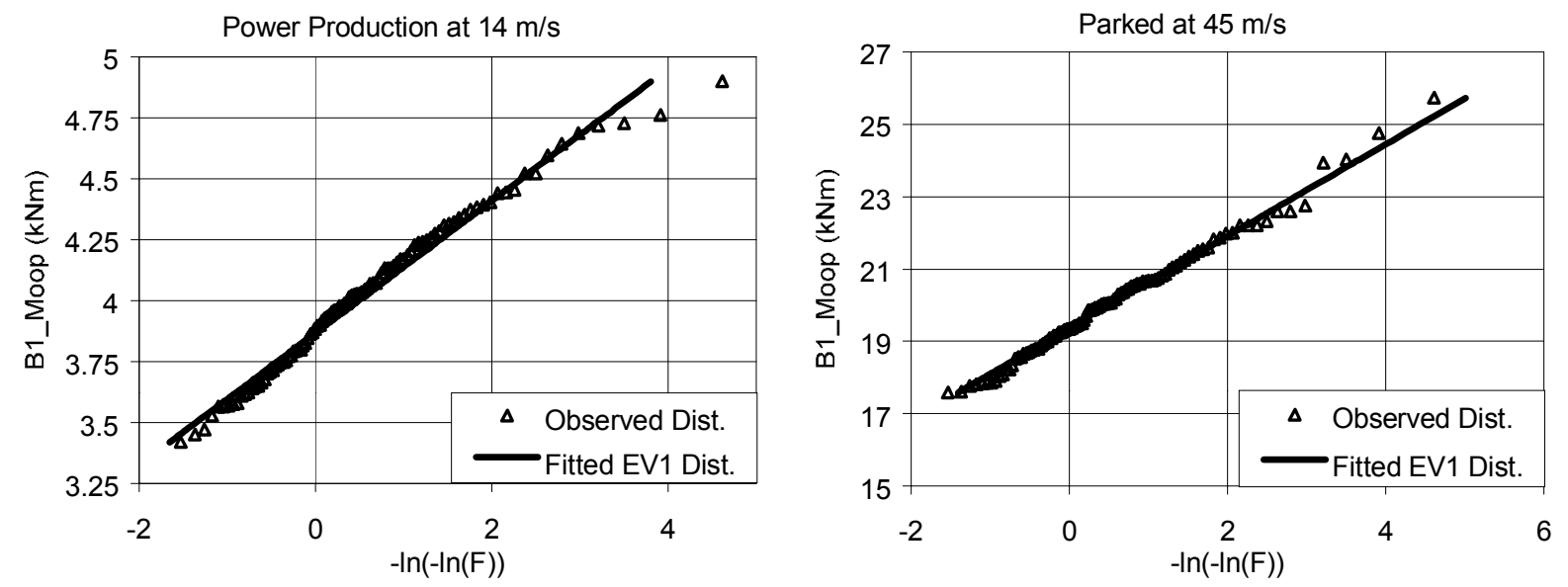

Figure 3. Extreme value fit of maximum out of plane bending moment from each of 100 10-minute runs

For the estimation of parameters in the EV1distribution, we shall use a simple method called the probability-weighted moment (PWM) procedure, recommended by Abild. ${ }^{12}$ Following this approach, the distribution parameters as well as the mean and standard deviation of the fitted EV1-distributions were determined. The resulting values are given in Table 5 . In all cases the fit between the data and the EV1distribution is good. The fit to data is illustrated in Figure 3 for the out-of-plane blade bending moment.

\section{CHARACTERISTIC VALUES}

Using the EV1-distribution model for the load extremes, it is now possible to define characteristic/representative values for the load extremes or the ultimate loads for the calculated load cases.

From extreme value statistics, it follows that the larger the sample (either from a longer simulation time or from more simulations) the larger is the expected value of the largest extreme for the sample. For a definition of a characteristic ultimate load we therefore need to define both the duration of the load case and the associated extreme value distribution parameter.
The choice of partial safety factors for the ultimate loads will depend on these definitions. These definitions are to some degree arbitrary, but will have consequences for the calibration of safety factors.

The following definitions of the characteristic/representative values for the ultimate loads will be analyzed and discussed:

- The characteristic/representative value is the expected maximum (extreme) value during a 10-minute period.

- The value corresponding to a 0.95 quantile in the distribution of maximum values, where each maximum value is obtained from a 10 -minute period.

- The value corresponding to a recurrence interval of a defined period of operation, taking into account the relative duration of the load case.

According to IEC 61400-1, the Parked load case is associated with $\mathrm{V}_{\text {ref, }}$, which is the 10-minute average wind speed with a 50 -year recurrence interval, i.e. the 10 -minute average wind speed that, on average, will occur once every 50 years. Definition 1 therefore seems the most appropriate for the parked load case. 
Table 6. Characteristic/Representative Load Values

\begin{tabular}{|c|c|c|c|c|c|c|c|c|}
\hline \multicolumn{2}{|c|}{ Power production - 14 m/s } & $\begin{array}{c}\text { Duration } \\
\text { hours }\end{array}$ & $\begin{array}{c}\text { B1_Moop } \\
\mathrm{kNm}\end{array}$ & $\begin{array}{c}\text { B1_Mip } \\
\mathrm{kNm}\end{array}$ & $\begin{array}{c}\text { YB_Fdw } \\
\mathrm{kN}\end{array}$ & $\begin{array}{c}\text { YB_Fcw } \\
\mathrm{kN}\end{array}$ & $\begin{array}{c}\text { YB_Mpitch } \\
\mathrm{k} N m\end{array}$ & $\begin{array}{c}\text { YB_Mroll } \\
\mathrm{kNm}\end{array}$ \\
\hline Def 1 & 10-min mean & & 4.02 & 2.91 & 4.43 & 0.74 & 8.48 & 3.90 \\
\hline Def 2 & 0.95 quantile & & 4.67 & 3.11 & 4.82 & 0.94 & 9.60 & 4.07 \\
\hline Def3 & Recurrence period & 1 & 4.33 & 3.00 & 4.61 & 0.83 & 9.01 & 3.98 \\
\hline "'" & "'" & 713 & 6.13 & 3.57 & 5.71 & 1.39 & 12.12 & 4.45 \\
\hline "'" & "'" & 35653 & 7.19 & 3.90 & 6.35 & 1.72 & 13.95 & 4.73 \\
\hline
\end{tabular}

\begin{tabular}{|c|c|c|c|c|c|c|c|c|}
\hline \multicolumn{2}{|c|}{ Power production - 20 m/s } & $\begin{array}{c}\text { Duration } \\
\text { hours }\end{array}$ & $\begin{array}{c}\text { B1_Moop } \\
\mathrm{kNm}\end{array}$ & $\begin{array}{c}\text { B1_Mip } \\
\mathrm{kNm}\end{array}$ & $\begin{array}{c}\text { YB_Fdw } \\
\mathrm{kN}\end{array}$ & $\begin{array}{c}\text { YB_Fcw } \\
\mathrm{kN}\end{array}$ & $\begin{array}{c}\text { YB_Mpitch } \\
\mathrm{kNm}\end{array}$ & $\begin{array}{c}\text { YB_Mroll } \\
\mathrm{kNm}\end{array}$ \\
\hline Def 1 & 10-min mean & & 5.14 & 3.35 & 6.21 & 1.10 & 10.23 & 5.24 \\
\hline Def 2 & 0.95 quantile & & 6.03 & 3.64 & 6.92 & 1.40 & 11.80 & 5.66 \\
\hline Def 4 & Recurrence period & 1 & 5.56 & 3.49 & 6.54 & 1.24 & 10.97 & 5.44 \\
\hline "'" & "'" & 143 & 7.43 & 4.10 & 8.03 & 1.89 & 14.29 & 6.32 \\
\hline "'" & "'" & 7139 & 8.87 & 4.57 & 9.18 & 2.39 & 16.86 & 7.01 \\
\hline
\end{tabular}

\begin{tabular}{|c|c|c|c|c|c|c|c|c|}
\hline \multicolumn{2}{|c|}{ Parked - 45 m/s } & $\begin{array}{c}\text { Duration } \\
\text { hours }\end{array}$ & $\begin{array}{c}\text { B1_Moop } \\
\mathrm{kNm}\end{array}$ & $\begin{array}{c}\text { B1_Mip } \\
\mathrm{kNm}\end{array}$ & $\begin{array}{c}\text { YB_Fdw } \\
\mathrm{kN}\end{array}$ & $\begin{array}{c}\text { YB_Fcw } \\
\mathrm{kN}\end{array}$ & $\begin{array}{c}\text { YB_Mpitch } \\
\mathrm{kNm}\end{array}$ & $\begin{array}{c}\text { YB_Mroll } \\
\mathrm{kNm}\end{array}$ \\
\hline Def 1 & 10-min mean & & 20.10 & 4.30 & 25.38 & 3.08 & 25.24 & 12.61 \\
\hline
\end{tabular}

The wind conditions for the Power Production load cases in IEC 61400-1 are either the normal wind conditions (frequently occurring during normal operation) with parameters chosen as being representative rather than defined by a certain quantile or recurrence interval, or the extreme wind conditions with recurrence intervals of 1 or 50 years.

However, it is not clear how to interpret this recurrence period in relation to load cases with a given mean wind speed and a relative duration with respect to the lifetime. Consider, for instance, a wind turbine operating in wind conditions characterized by the Rayleigh distribution with mean $9 \mathrm{~m} / \mathrm{s}$. In several of the load cases the load shall be calculated at rated and cut-out wind speed, $V_{r}$ and $V_{\text {out }}$, respectively. Assuming a binwidth of $2 \mathrm{~m} / \mathrm{s}$, the relative duration at $\mathrm{V}_{\mathrm{r}}$ and $\mathrm{V}_{\text {out }}$ are

$\mathrm{V}_{\mathrm{r}}=14 \mathrm{~m} / \mathrm{s} \quad \mathrm{P}\{13 \mathrm{~m} / \mathrm{s}<\mathrm{V}<15 \mathrm{~m} / \mathrm{s}\}=8.14 \%$

$\mathrm{V}_{\text {out }}=20 \mathrm{~m} / \mathrm{s} \quad \mathrm{P}\{19 \mathrm{~m} / \mathrm{s}<\mathrm{V}<21 \mathrm{~m} / \mathrm{s}\}=1.63 \%$

The most reasonable interpretation of a recurrence period of 1 or 50 years for the wind/load conditions at a given wind speed would be to take into account the relative duration. Thus a recurrence period of 1 year at $\mathrm{V}_{\mathrm{r}}$ and $\mathrm{V}_{\text {out }}$ would correspond to a duration of the load case of 713 hours and 143 hours, respectively rather than 8760 hours. Note that the relative duration depends on the bin-width, which then needs to be defined and agreed.

Shown in Table 6 are the load values for the six major wind turbine loads already defined.

The first two definitions may apply for normal wind conditions, while recurrence periods of 1 and 50 years may represent extreme wind conditions. The recurrence intervals shown correspond to 1 hour of operation at the wind speed, and to 1 or 50 years of wind turbine operation, taking into account the relative duration of the load case.

A similarly important question, namely how to determine the number of simulation runs required for the determination of characteristic value of the ultimate loads, however, remains. Ideally, the uncertainty of the characteristic value due to the numerical scheme for calculation of ultimate loads should be insignificant compared to all other uncertainties in the design verification process.

In order to assess the uncertainty from the simulation scheme, we shall calculate the confidence interval for the already discussed definitions of the characteristic values of the ultimate loads. The approach is described in Madsen et al. ${ }^{8}$

Assume now that the requirement is that the characteristic value of the ultimate load shall be determined such that the $95 \%$ confidence interval for all loads (except the rotor force perpendicular to the wind direction) is less than $10 \%$ of the characteristic value. The number of necessary simulations of length 10 minutes (necessary sample size) to obtain this confidence interval has been determined and is shown in Table 7. In order to reduce the confidence interval to $5 \%$ the sample size shall be four times the values shown.

In the actual design verification situation it is doubtful that more than a few (5) simulations will be made for each load case. We may thus conclude that this direct approach is only feasible for the determination of the 10-minute mean of the extreme value.

If another model for the determination of the characteristic ultimate loads, which would require a smaller sample size or number of simulation runs, could be derived, this would have beneficial consequences for the verification process and the size of the partial-load 
Table 7. Sample Size Requirements for a $10 \%$ Confidence Interval

\begin{tabular}{|l|c|c|c|}
\hline \multirow{4}{*}{ Load case } & $\begin{array}{c}\text { Definition of } \\
\text { ultimate value }\end{array}$ & $\begin{array}{c}\text { Duration } \\
\text { hours }\end{array}$ & $\begin{array}{c}\text { Sample size } \\
10 \text { min run }\end{array}$ \\
\hline \multirow{4}{*}{$\begin{array}{l}\text { Power } \\
\text { production - } \\
14 \mathrm{~m} / \mathrm{s}\end{array}$} & 10 -min mean & & 3 \\
\cline { 2 - 4 } & 0.95 quantile & & 15 \\
\cline { 2 - 4 } & Recurr. period & 1 & 7 \\
\cline { 2 - 4 } & "'" & 713 & 60 \\
\hline \multirow{4}{*}{$\begin{array}{l}\text { Power } \\
\text { production - } \\
20 \mathrm{~m} / \mathrm{s}\end{array}$} & 10 -min mean & 35653 & 92 \\
\cline { 2 - 4 } & 0.95 quantile & & 4 \\
\cline { 2 - 4 } & Recurr. period & 1 & 17 \\
\cline { 2 - 4 } & "'" & 143 & 50 \\
\cline { 2 - 4 } & "' & 7139 & 84 \\
\hline Parked - 45 m/s & 10 -min mean & & 3 \\
\hline
\end{tabular}

safety factors. Such a model will be presented in the next section.

The choice of definition of the characteristic ultimate load together with the choice of partial load safety factors is to some degree a political one, to be taken by standards committees or similar bodies. For the Power Production load cases the definitions determined from a recurrence period based on the assumed operational modes of the wind turbine seems to be the most conceptually satisfying. The values, however, are based on extrapolation far beyond the observed extreme values from the simulations, which hardly can be justified without experimental verification. A better way could be to define the characteristic load as the mean extreme during a 10-minute simulation, using a turbulence intensity of the recurrence period in question.

Finally, it is noted that apart from the in-plane blade bending moments, the ultimate loads are found for the parked rotor load case at the 50 -year wind speed. The blade points vertically upward in the simulations, and gravity does not contribute to the in-plane blade bending moment.

\section{SEMI-ANALYTICAL PREDICTION OF EXTREMES}

In the following we shall attempt to reduce the statistical uncertainty associated with the distribution of extremes by introducing further assumptions on the nature of the turbulence response simulations. We shall only look at the parked load case, where the mean and the standard deviation are constant with time. In Mad$\operatorname{sen}^{8}$ it is shown, how the approach can be extended to the operation load cases, taking into account the periodic variation of the signal mean and standard deviation.

The approach is inspired by Davenport. ${ }^{7} \mathrm{He}$ assumed that the structural response to wind turbulence was a stationary Gaussian process, and derived an

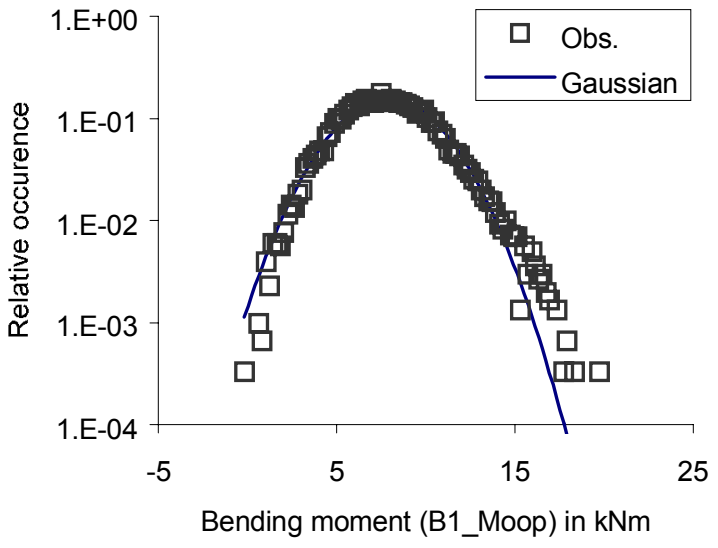

Figure 4. Comparison of actual occurrences and the Gaussian probability density function

asymptotic solution for the distribution of the largest extreme during the period T. Before presenting a semianalytical method for the prediction of the distribution of extremes we will take a closer look at the characteristics of the turbulence response signal for one of the simulation runs and the validity of the assumptions.

The statistics shown in Tables 2-4 show a definite skewness in several of the response realizations. Except for the wind speed signal and the tower force perpendicular to the wind direction, the probability densities are definitely skewed with a significant effect in the tails. The histogram for the out-of-plane blade bending moment for a 10-minute run in the form of the relative number of occurrences is shown in Figure 4 together with the Gaussian probability density functions with the same first two moments. Note that the skewness causes the number of occurrences in the tail with the largest absolute value of the load to be higher than the Gaussian assumption would predict.

Therefore we will develop an analytical solution to the distribution of extremes taking into account that the signal generating the extremes is skewed. Since a Gaussian stochastic process does not have skewness, we shall instead assume that the generated response signals $\mathrm{Z}(\mathrm{t})$ are of the form

$$
Z(t)=\zeta(t)+\eta(t)\left(X(t)+\varepsilon X(t)^{2}\right) ; \quad \varepsilon<<1
$$

where $\mathrm{X}(\mathrm{t})$ is a normalized Gaussian process, and $\zeta$ and $\eta$ are parameters that determine the mean and standard deviation. In this section $\zeta$ and $\eta$ shall be considered constants, i.e., independent of time.

Assuming that we know the mean, variance, and skewness of the response process $Z(t)$, the first order approximation of the parameter $\varepsilon, \zeta, \eta$, and $v_{0 x}$, see Madsen, ${ }^{8}$ are

$$
\varepsilon \cong \frac{\gamma}{6}
$$




$$
\begin{gathered}
\eta \cong \sigma_{Z} \\
\varsigma \cong \mu_{Z}-\varepsilon \sigma_{Z} \\
v_{\mu_{Z}}^{Z}(t) \cong v_{0}^{X}
\end{gathered}
$$

The resulting mean and variance of the asymptotic EV1 distribution of the process $\mathrm{Z}(\mathrm{t})$ becomes

$$
\begin{aligned}
& E\left\{Z_{T}^{\max }\right\}=\beta+\frac{\gamma_{E}}{\alpha}= \\
& \mu_{Z}+\sigma_{Z}\left(\sqrt{2 \ln \left(v_{0} T\right)}+\varepsilon\left(2 \ln \left(v_{0} T\right)-1\right)\right)_{+} \\
& \frac{0.5772 \sigma_{Z}\left(1+2 \varepsilon \sqrt{2 \ln \left(v_{0} T\right)}\right)}{\sqrt{2 \ln \left(v_{0} T\right)}} \\
& \operatorname{Var}\left\{Z_{T}^{\max }\right\}=\frac{\pi^{2}}{6 \alpha^{2}}=\frac{\pi^{2} \sigma_{Z}^{2}\left(1+2 \varepsilon \sqrt{2 \ln \left(v_{0} T\right)}\right)^{2}}{12 \ln \left(v_{0} T\right)}
\end{aligned}
$$

The prediction of the mean value and the standard deviation of the largest extreme during the parked load case at $45 \mathrm{~m} / \mathrm{s}$, using the Gaussian assumption and using the non-linearity correction described above, are compared in Table 8 to the mean and standard deviation calculated directly from the observed extremes.

The uncertainty has been considerably reduced as can be seen in Table 9, showing the $95 \%$ confidence interval for the expected value of the largest extreme during 10 minutes for the parked load case. The confidence interval is given as a percentage of the mean value. The parameter $\mathrm{n}$ is the sample size, i.e., the number of simulation runs. Using the semi-analytical approach with the non-linearity correction based on statistics from two runs gives the same width of the confidence interval as 15 runs combined with the direct estimate of the expected value of the largest extreme.

The use of the semi-analytical approach with the non-linearity correction is recommended to provide a reasonably small uncertainty with a feasible number of simulation runs.

\section{COMPARISON WITH IEC}

The latest revision of IEC 61400-1 requires the ultimate loads to be determined using both turbulence simulations and extreme wind events/gusts during power production and using an extreme wind determined as a short-term-average wind speed for the parked load case. In the following we shall compare the ultimate loads using the standard directly with the ultimate loads based on turbulence response simulations.

The IEC ultimate loads were calculated ${ }^{13}$ using the same ADAMS-model as was used for the turbulence response simulations. Load cases without any internal or external faults were analyzed for the design situa-

\begin{tabular}{|c|c|c|c|c|c|c|c|c|}
\hline \multicolumn{2}{|c|}{ Estimates from all runs } & \multirow{2}{*}{$\begin{array}{c}\begin{array}{c}\text { WindSpd } \\
\mathrm{m} / \mathrm{s}\end{array} \\
0.44\end{array}$} & \multirow{2}{*}{$\begin{array}{c}\begin{array}{c}\text { B1_Moop } \\
\text { kNm }\end{array} \\
0.79\end{array}$} & \multirow{2}{*}{$\frac{\begin{array}{c}\text { B1_Mip } \\
\mathrm{kNm}\end{array}}{4.10}$} & \multirow{2}{*}{$\frac{\mathrm{YB}_{\mathrm{kN}}^{\mathrm{FNdw}}}{0.62}$} & \multirow{2}{*}{ 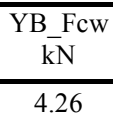 } & \multirow{2}{*}{$\begin{array}{c}\begin{array}{c}\text { YB_Mpitch } \\
\mathrm{kNm}\end{array} \\
0.64\end{array}$} & \multirow{2}{*}{$\begin{array}{c}\begin{array}{c}\text { YB_Mroll } \\
\mathrm{kNm}\end{array} \\
1.50\end{array}$} \\
\hline \multirow{4}{*}{$\begin{array}{l}\text { EV1-dist. } \\
\text { From } 100 \\
\text { time series }\end{array}$} & $\overline{a l f a}$ & & & & & & & \\
\hline & beta & 70.50 & 19.37 & 4.16 & 24.46 & 2.95 & 24.34 & 12.22 \\
\hline & mean & 71.81 & 20.10 & 4.30 & 25.38 & 3.08 & 25.24 & 12.61 \\
\hline & st.dev. & 2.91 & 1.63 & 0.31 & 2.05 & 0.30 & 2.01 & 0.86 \\
\hline \multirow{3}{*}{$\begin{array}{l}\text { Simple } \\
\text { Daven-port }\end{array}$} & Peak factor & 3.67 & 3.89 & 4.12 & 3.87 & 3.95 & 3.94 & 3.78 \\
\hline & \begin{tabular}{|l|} 
Est max mean \\
\end{tabular} & 70.96 & 18.03 & 4.07 & 23.42 & 2.77 & 22.92 & 11.40 \\
\hline & Est max st.dev & 2.56 & 0.89 & 0.21 & 1.34 & 0.23 & 1.29 & 0.56 \\
\hline \multirow{4}{*}{$\begin{array}{l}\text { Non-linearity } \\
\text { correction }\end{array}$} & Peak factor & 3.94 & 4.64 & 4.58 & 4.38 & 3.99 & 4.42 & 4.67 \\
\hline & Eps & 0.00 & 0.05 & 0.03 & 0.04 & 0.00 & 0.03 & 0.07 \\
\hline & Est max mean & 72.23 & 19.99 & 4.37 & 25.40 & 2.80 & 24.73 & 12.80 \\
\hline & Est max st.dev. & 2.95 & 1.25 & 0.26 & 1.70 & 0.24 & 1.61 & 0.83 \\
\hline
\end{tabular}
tions Power Production (DLC 1.3, 1.6, 1.7, 1.8 and 1.9) and Parked (DLC 6.1) for the defined gust models and

\begin{tabular}{|c|c|c|c|c|c|c|c|c|}
\hline \multicolumn{2}{|c|}{$95 \%$ confidence intervals } & \multirow{2}{*}{$\begin{array}{c}\begin{array}{c}\text { WindSpd } \\
\mathrm{m} / \mathrm{s}\end{array} \\
72.23\end{array}$} & \multirow{2}{*}{ 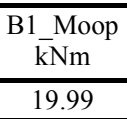 } & \multirow{2}{*}{$\frac{\begin{array}{c}\text { B1_Mip } \\
\mathrm{kNm}\end{array}}{4.37}$} & \multirow{2}{*}{$\frac{{ }_{\mathrm{KN}}^{\mathrm{YB} F d w}}{25.40}$} & \multirow{2}{*}{$\begin{array}{c}\begin{array}{c}\text { YB_Fcw } \\
\mathrm{kN}\end{array} \\
2.80\end{array}$} & \multirow{2}{*}{$\frac{\begin{array}{c}\text { YB_Mpitch } \\
\text { kNm }\end{array}}{24.73}$} & \multirow{2}{*}{$\begin{array}{c}\begin{array}{c}\text { YB_Mroll } \\
\mathrm{kNm}\end{array} \\
12.80\end{array}$} \\
\hline Semi- & Est. max mean & & & & & & & \\
\hline analytical & St. error & 1.33 & 0.57 & 0.07 & 0.78 & 0.09 & 0.68 & 0.31 \\
\hline & Interval $+/-\mathrm{n}=1$ & $3.6 \%$ & $5.6 \%$ & $3.1 \%$ & $6.1 \%$ & $6.1 \%$ & $5.4 \%$ & $4.7 \%$ \\
\hline & Interval $+/-n=2$ & $2.6 \%$ & $4.0 \%$ & $2.2 \%$ & $4.3 \%$ & $4.3 \%$ & $3.8 \%$ & $3.3 \%$ \\
\hline \multirow{4}{*}{$\begin{array}{l}\text { Statistics from } \\
100 \text { time } \\
\text { series }\end{array}$} & Est. max mean & 71.81 & 20.10 & 4.30 & 25.38 & 3.08 & 25.24 & 12.61 \\
\hline & St. error & 2.91 & 1.63 & 0.31 & 2.05 & 0.30 & 2.01 & 0.86 \\
\hline & Interval $+/-\mathrm{n}=1$ & $7.9 \%$ & $15.9 \%$ & $14.3 \%$ & $15.9 \%$ & $19.1 \%$ & $15.6 \%$ & $13.3 \%$ \\
\hline & Interval $+/-n=15$ & $2.1 \%$ & $4.1 \%$ & $3.7 \%$ & $4.1 \%$ & $4.9 \%$ & $4.0 \%$ & $3.4 \%$ \\
\hline
\end{tabular}
assuming wind turbine Class IA. The analyzed load cases assume the parameters in Table 10.

The IEC 61400-1 does not specify the turbulence

Table 8. Comparison of Prediction Methods

Table 9. Comparison of Confidence Interval at Different Sample Sizes 
Table 10. Load Case Parameters

\begin{tabular}{|l|c|c|c|c|}
\hline $\begin{array}{l}\text { Design situa- } \\
\text { tion- Load } \\
\text { case }\end{array}$ & $\begin{array}{l}\text { Wind } \\
\text { speed } \\
(10 \mathrm{~min} \\
\text { aver.) }\end{array}$ & $\begin{array}{l}\text { Power } \\
\text { law } \\
\text { expo- } \\
\text { nent } \alpha\end{array}$ & $\begin{array}{l}\text { Tur- } \\
\text { bulence } \\
\text { inten- }_{\text {sity } \mathrm{I}_{\mathrm{u}} *}\end{array}$ & $\begin{array}{l}\text { Turbulence } \\
\text { standard } \\
\text { deviation } \\
\sigma_{1}{ }^{*}\end{array}$ \\
\hline $\begin{array}{l}\text { Power Produc- } \\
\text { tion (DLC } 1.3, \\
1.6,1.7,1.8 \text { and } \\
1.9)\end{array}$ & $14 \mathrm{~m} / \mathrm{s}$ & 0.2 & $18.4 \%$ & $2.58 \mathrm{~m} / \mathrm{s}$ \\
\hline $\begin{array}{l}\text { Power Produc- } \\
\text { tion (DLC } 1.6, \\
1.7 \text { and } 1.8)\end{array}$ & $20 \mathrm{~m} / \mathrm{s}$ & 0.2 & $16.5 \%$ & $3.30 \mathrm{~m} / \mathrm{s}$ \\
\hline $\begin{array}{l}\text { Parked (DLC } \\
6.1)\end{array}$ & $50 \mathrm{~m} / \mathrm{s}$ & 0.11 & $(11 \%)$ & $(5.5 \mathrm{~m} / \mathrm{s})$ \\
\hline
\end{tabular}

*longitudinal turbulence component

parameters for load case 6.1 , but simply requires the quasi-static loads to be calculated for a short-term average wind speed of $1.4 * \mathrm{~V}_{\text {ref }}=70 \mathrm{~m} / \mathrm{s}$. However, assuming that the wind profile power law has been fitted at hub height and that we have neutral atmospheric stratification with both the wind profile and the turbulence intensity determined by the surface roughness $\mathrm{z}_{0}$, see ISO4354. ${ }^{1}$

$$
\begin{gathered}
V(z)=k \ln \left(z / z_{0}\right) \\
I_{u}=\frac{1}{\ln \left(z / z_{0}\right)}
\end{gathered}
$$

A power law exponent $\alpha=0.11$ corresponds to the listed turbulence.

The turbulence response simulations for the power production load cases were calculated for a windprofile power-law exponent of 0.2 and turbulence intensity for the longitudinal component of $16.6 \%$. The 14 and $20 \mathrm{~m} / \mathrm{s}$ wind speeds correspond to the rated and the cut-out wind speeds. Only the turbulence level is different, and assuming that the stochastic part of the response is proportional to the turbulence level (expressed as the standard deviation of the longitudinal component), we shall use the expression:

$$
S_{\text {extreme }}^{\text {scaled }}=\hat{S}+\left(S_{\text {extreme }}-\hat{S}\right) \gamma_{1}
$$

$\hat{S}$ is the average absolute max of the azimuth averaged signal for the blade bending moments (1.29 and $1.98 \mathrm{kNm}$ for B1_Moop at 14 and $20 \mathrm{~m} / \mathrm{s}$, respectively and 1.98 and $2.10 \mathrm{kNm}$ for B1_Mip at 14 and $20 \mathrm{~m} / \mathrm{s}$, respectively) and the mean value for the rest of the loads. The latter approximation is reasonable, since their azimuth-averaged variation is only a few percent of the mean. $\gamma_{1}$ is the ratio of the turbulence intensities, which is 1.11 and 0.99 at 14 and $20 \mathrm{~m} / \mathrm{s}$, respectively.

Similarly, the turbulence-response simulations for the parked load case were calculated for a wind profile power law exponent of 0.2 and a turbulence intensity for the longitudinal component of 0.17 , resulting in a
Table 11. Comparison of Scaled Extreme Loads

\begin{tabular}{|c|c|c|c|c|c|}
\hline \multirow{2}{*}{ Load } & \multicolumn{2}{|c|}{$\begin{array}{l}\text { Scaled simulation } \\
\text { extreme - } 14 \mathrm{~m} / \mathrm{s}\end{array}$} & \multicolumn{2}{|c|}{$\begin{array}{l}\text { Scaled simulation } \\
\text { extreme }-20 \mathrm{~m} / \mathrm{s}\end{array}$} & \multirow{2}{*}{$\begin{array}{c}\text { IEC } \\
\text { extreme }\end{array}$} \\
\hline & $\begin{array}{l}10-\mathrm{min} \\
\text { mean }\end{array}$ & $\begin{array}{l}0.95 \\
\text { quant. }\end{array}$ & $\begin{array}{l}10-\mathrm{min} \\
\text { mean }\end{array}$ & $\begin{array}{l}0.95 \\
\text { quant. }\end{array}$ & \\
\hline B1_Moop (kNm) & 4.32 & 5.04 & 5.12 & 6.01 & 3.90 \\
\hline B1_Mip (kNm) & 3.01 & 3.23 & 3.34 & 3.63 & 2.83 \\
\hline YB_Fdw $(\mathrm{kN})$ & 4.66 & 5.09 & 6.19 & 6.90 & 5.74 \\
\hline YB_Fcw $(\mathrm{kN})$ & 0.82 & 1.05 & 1.09 & 1.39 & 0.33 \\
\hline YB_Mpitch $(\mathrm{kNm})$ & 9.73 & 10.98 & 10.15 & 11.71 & 7.49 \\
\hline YB_Mroll $(\mathrm{kNm})$ & 4.64 & 4.82 & 5.19 & 5.61 & 5.54 \\
\hline
\end{tabular}
from Turbulence Response Simulations and IEC Power Production Load Cases

grid-point standard deviation of $7.47 \mathrm{~m} / \mathrm{s}$. The $10 \mathrm{~min}-$ ute average wind speed was $45 \mathrm{~m} / \mathrm{s}$. Hence, we need to adjust for the mean wind speed, the profile, and the turbulence level.

As for the power production load cases, we shall scale the simulation results for the comparison. As the basis for the scaling we shall choose the velocity pressure

$$
\begin{aligned}
& p(y, z, t)=1 / 2 \rho V^{2}=1 / 2 \rho\left(V_{0}+V(y, z)+u+v+w\right)^{2} \\
& \quad \cong 1 / 2 \rho V_{0}^{2}+\rho V_{0}(V(y, z)+u+v+w)
\end{aligned}
$$

We shall therefore use the expression

$$
S_{\text {extreme }}^{\text {scaled }}=S_{\text {gravity }}+\left(\bar{S}-S_{\text {gravity }}\right) \gamma_{1}+\left(S_{\text {extreme }}-\bar{S}\right) \gamma_{2}
$$

in which the gravity component to the rotor moments are excluded from the scaling $(-0.98 \mathrm{kNm}$ and -0.43 $\mathrm{kNm}$ for the pitching and the rolling moment, respectively), $\gamma_{1}$ is the ratio of the 10 -minute average wind speeds squared except for the pitching moment, where $\gamma_{1}$ is the ratio of the power law exponent times the 10minute average wind speeds squared and $\gamma_{2}$ is the ratio of the turbulence standard deviation times the ratio of the average wind speeds.

In the comparison of the power production load cases, only the extremes corresponding to the mean extreme during 10 minutes and the 0.95 quantile for the 10 minute extreme are shown in Table 11.

Note that the blade bending moments and especially the rotor pitching moment are larger from the simulations than for the extreme wind gusts of the IEC standard. This suggests that for this wind turbine, these IEC ultimate load cases are very benign and not critical.

The results of the comparison for the parked load case are shown in Table 12. All loads based on the turbulence response simulations, except for the rolling moment, are larger than those obtained from the IEC requirements. 
Table 12. Comparison of Scaled Extreme Loads from Turbulence Response Simulations and IEC for Parked Load Case

\begin{tabular}{|l|c|c|}
\hline \multicolumn{1}{|c|}{ Load } & $\begin{array}{c}\text { Scaled simu- } \\
\text { lation extreme }\end{array}$ & $\begin{array}{c}\text { IEC } \\
\text { extreme }\end{array}$ \\
\hline B1_Moop $(\mathrm{kNm})$ & 17.51 & 14.97 \\
\hline B1_Mip $(\mathrm{kNm})$ & 3.63 & 3.03 \\
\hline YB_Fdw $(\mathrm{kN})$ & 21.46 & 17.93 \\
\hline YB_Fcw $(\mathrm{kN})$ & 2.39 & 0.27 \\
\hline YB_Mpitch $(\mathrm{kNm})$ & 19.28 & 14.83 \\
\hline YB_Mroll $(\mathrm{kNm})$ & 10.30 & 10.67 \\
\hline
\end{tabular}

\section{CONCLUSIONS}

The results presented demonstrate a significant statistical variation in ultimate loads predicted by an aeroelastic code with simulated turbulence input. Depending on the definition of the characteristic load a high number of simulations are necessary for a precise estimate.

It is concluded that prediction of ultimate loads using turbulence response simulations must be combined with statistical methods. Basic extreme value statistics have been applied for possible definition of characteristic load values. A semi-analytical model for the extremes from a non-Gaussian process has been derived, and good accuracy and efficiency demonstrated.

Although the comparison with the IEC loads is valid only for this or similar wind turbines, it raises some questions. During power production the ultimate loads are determined by load case 1.1, with normal turbulence model at rated and cut-out wind speeds. Extrapolation to extreme 1 and 50 year events will give much higher ultimate loads than the IEC extreme wind gusts from the load cases DLC 1.3, 1.6, 1.7, 1.8 and 1.9.

The ultimate loads during the parked load case, DLC 6.1, seem to be under-predicted using the quasistatic extreme wind model in the IEC standard. While the effect of averaging the turbulent wind field is much smaller for a wind turbine of this size than for a large turbine, the comparison indicates that the extreme wind model is unsatisfactory, especially for asymmetrical loads. A requirement for turbulence simulations is recommended.

\section{ACKNOWLEDGEMENTS}

The work reported here was carried out while the first author was a visiting scientist at the National Renewable Energy Laboratory's National Wind Technology Center in the USA. Sandy Butterfield and Bob Thresher at NREL are thanked for making this visit possible and for good discussions. Also Paul Veers of Sandia National Laboratories and Bill Holley are thanked for their comments and contributions to the work.
DOE has supported this work through the National Renewable Energy Laboratory under contract number DE-AC36-83CH10093.

\section{REFERENCES}

${ }^{1}$ ISO 4354:1997(E) Wind Actions on Structures

2 A.G. Davenport, The Application of Statistical Concepts to the Wind Loading of Structures, Proc. Inst. of Civil Engineers, 19, 1961.

3 P.H. Madsen, Design Turbulence Loads on Horizontal-Axis Wind Turbines, Risø-M-2581, Risø National Laboratory, 1986.

${ }^{4}$ DS 472, Danish Design Code for Wind Turbine Constructions (in Danish), NP-209-N, Normstyrelsens Publikationer, København, 1. edition, 1992.

5 IEC 61400-1 ed. 2, 88/82/CDV: Wind Turbine Generator Systems - Part 1: Safety Requirements.

${ }^{6}$ K. Thomsen and P.H. Madsen, Application of Statistical Methods to Extreme Loads for Wind Turbines, Proc. EWEC'97 European Wind Energy Conference \& Exhibition, 6-9 October 1997, Dublin, Ireland.

${ }^{7}$ A.G. Davenport, Note on the Distribution of the Largest Value of a Random Function with Applications to Gust Loading, Proc. Inst. of Civil Engineers, 28, 1964.

${ }^{8}$ P.H. Madsen, K. Pierce and M. Buhl, Wind Turbine Extreme Loads, Draft Report, NREL, Golden CO, 1998

${ }^{9}$ Schepers et al., Final Report of IEA Annex XIV: Field Rotor Aerodynamics, ECN-C--97-027, Netherlands Energy Foundation ECN, Petten, the Netherlands, 1997.

${ }^{10}$ Hansen, A.C., Users Guide to the Wind Turbine Dynamics Computer Programs YawDyn and AeroDyn for $A D A M S ®$, Mechanical Engineering Dept., University of Utah, Salt Lake City, Utah, 1996.

${ }^{11}$ Gumbel, E.J., Statistics of Extremes, Columbia University Press, New York, 1958.

12 Abild, J., "Application of the Wind Atlas Method to Extremes of Wind Climatology," Risø-R.722(EN), Risø National Laboratory, Roskilde, Denmark, 1994.

${ }^{13}$ David Laino, University of Utah, Private Communication, 1998. 